\title{
Study on Processing of High Precision Graphite Ball with Four Axis Ball Grinder
}

\author{
Bin ZHOU, Yinan XIA \\ Department of Precision Instrument \\ Tsinghua University \\ Beijing, China \\ e-mail: zhoub@mail.tsinghua.edu.cn,xiayn15@mails.tsinghua.edu.cn
}

\begin{abstract}
This paper implements a four axis ball grinder to the high precision processing of graphite balls. In this paper, the mechanism of grinding effect by the four axis ball grinding method was analyzed. The influence from the size of lapper, the pressure and the grinding coefficient was studied. Then this paper improved the structure of the four axis ball grinder with pressure and speed control unit promoted. Through experiments, the processing uniformity under different lapper radius and different lapper pressure was compared. Finally, 5 um roundness graphite ball was got and a set of empirical parameters were summed up by the experiments.
\end{abstract}

Keywords-graphite ball; four axis ball grinding; roundness; roughness

\section{INTRODUCTION}

Graphite material has excellent electrical and thermal conductivity. As a carbon elemental, it has stable chemical properties and low expansion rate at high temperature, so that it can be used as high-temperature and high-precision mold material ${ }^{[1]}$. The spherical graphite mold can be applied to millimeter-scale quartz hemispherical resonator's thermal forming processing, and the high precision quartz hemisphere resonator can be used as kinds of sensors. At present, the processing of graphite material mainly adopts machining method, which can achieve 0.17um surface roughness by high-speed grinding ${ }^{[2]}$ and surface roughness $10 \sim 15 \mathrm{~nm}$ by precision polishing ${ }^{[3]}$. However, because of the low hardness of graphite materials, it is difficult to obtain high topography accuracy by traditional machining method. Also it is difficult to achieve high-precision processing for the spherical or concave spherical graphite parts. High precision machining to hard materials (such as steel ${ }^{[4]}$ ) is usually done by four axis ball grinding. It has been reported to achieve 0.1 um roundness and $0.9 \mathrm{~nm}$ surface roughness ${ }^{[7]}$. However, there is no report about four axis ball grinding applied to graphite ball processing. At the same time, there are still some shortcomings in the analysis of the four axis ball grinding accuracy.

Based on the above idea of hard material processing, this paper put forward a method of processing graphite balls with four axis ball grinder. By studying the mechanism, the structure of four axis ball grinder has been improved. A set of processing technology for graphite balls was designed. A batch of graphite balls below 5um of roundness was finally processed to meet the requirements for the mold of the micro hemisphere quartz resonator.

\section{INTRODUCTION TO THE FOUR AXIS BALL GRINDER}

The abstract model of the four axis ball grinder are shown in Fig.1(a). The four lappers ranges from Axis I to Axis IV are directed from the vertex of the tetrahedron to the center of the tetrahedron, where the ball is processed. The angle between the four axis is $109^{\circ} 28^{\prime}$ because of the perfect symmetry of tetrahedron. Neglecting the ball gravity $\left(<10^{\wedge}-5 \mathrm{~N}\right)$, the ball is balanced when the four axis pressure are equal.

As shown in Fig.1(c), lappers are cup-shaped, so that the ball can be fixed at the tetrahedron center by the lappers. The friction between one lapper and the ball produces a moment along the axis of the lapper. In the initial state,

$$
T_{0}=\left|\oint \frac{k_{f} F_{N}}{2 \pi r} \mathbf{r} \times \mathrm{d} \mathbf{l}\right|=\int_{0}^{2 \pi} \frac{k_{f} F_{N}}{2 \pi} r \mathrm{~d} \theta=r k_{f} F_{N}
$$

Where $k_{f}$ means friction factor, $F_{N}$ means the pressure from lappers to the ball, and $r$ means lappers' radius. With this moment, the ball begins to rotate until its movement stabilized.

In order to get the ball grinded, there must be the relative movement between the ball and the lappers so that the axis of the ball's rotation can't be the same as one of the lappers. With geometrical analysis, only two lappers forward and two lappers backward status can achieve this.

TABLE I. THE RELATIONSHIP BETWEEN THE BALL AND THE LAPPERS' ROTATING DIRECTION

\begin{tabular}{|c|c|c|c|c|c|}
\hline $\begin{array}{c}\text { Axis } \\
\text { I }\end{array}$ & $\begin{array}{c}\text { Axis } \\
\text { II }\end{array}$ & $\begin{array}{c}\text { Axis } \\
\text { III }\end{array}$ & $\begin{array}{c}\text { Axis } \\
\text { IV }\end{array}$ & $\begin{array}{c}\text { Ball } \\
\text { Axis }\end{array}$ & $\begin{array}{c}\text { Stage } \\
\text { Num }\end{array}$ \\
\hline+ & + & - & - & $\mathrm{M}_{1} \mathrm{~N}_{1}+$ & 1 \\
\hline+ & - & - & + & $\mathrm{M}_{2} \mathrm{~N}_{2}+$ & 2 \\
\hline+ & - & + & - & $\mathrm{M}_{3} \mathrm{~N}_{3}+$ & 3 \\
\hline- & - & + & + & $\mathrm{M}_{1} \mathrm{~N}_{1-}$ & 4 \\
\hline- & + & + & - & $\mathrm{M}_{2} \mathrm{~N}_{2-}$ & 5 \\
\hline- & + & - & + & $\mathrm{M}_{3} \mathrm{~N}_{3-}$ & 6 \\
\hline
\end{tabular}

To grind the ball evenly, the axis of the ball's rotation must switch frequently during the processing period. The relationship between the balls' stabilized rotation direction and the lappers' rotation direction is shown in Table. I . When switching the lappers' rotation direction from stage 1 to stage 6 , the graphite ball will go through 6 different kinds 
of interaction with the lappers, so that it can be grinded as evenly as possible.

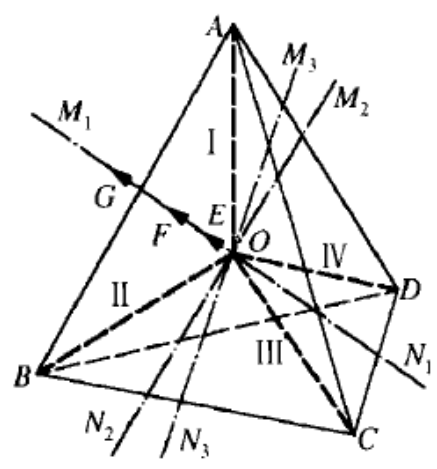

(a)

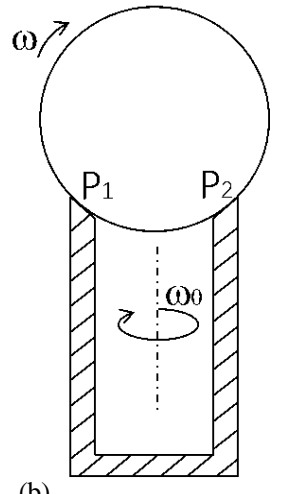

(b)
Figure 1. The mechanism of 4 axis ball grinder.

\section{ANALYSIS AND IMPROVEMENT OF FOUR AXIS BALL GRINDER}

Considering the Preston grinding removal theory ${ }^{[8]}$, the grinding rate at each contact point is proportional to the pressure and the relative velocity, i.e.

$$
\frac{\mathrm{d} H}{\mathrm{~d} t}=k \cdot p \cdot v
$$

According to the grinding model above, the grinding rate is determined by the lapper pressure $p$, the grinding coefficient $k$ and the relative speed $v$ between the ball and the lappers.

Traditional four axis ball grinder, shown in Fig. 2, consist of the basement, four dynamos, four lappers fixed to the dynamos, four photo-electric gate to measure the speed of dynamos, an open-loop dynamo controller to keep the lappers speed constant, and four identical weight-pulley structures to ensure the 4 axial pressures equal.

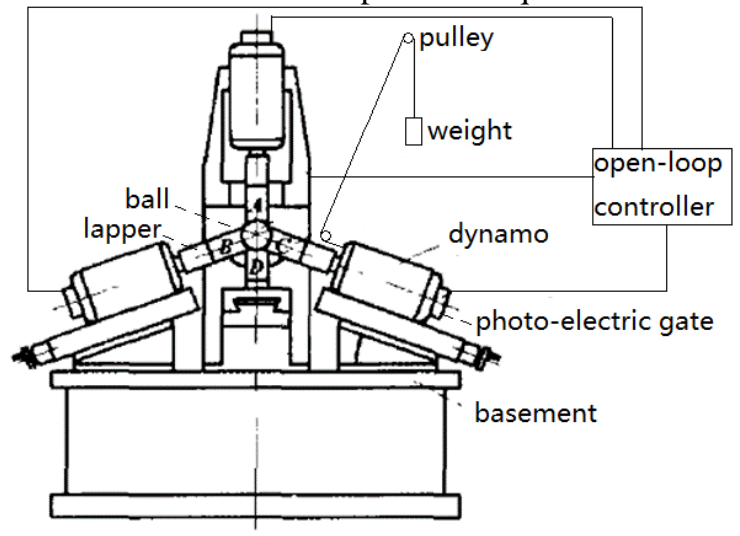

Figure 2. Structure of traditional four axis ball grinder.

This structure is easy to construct, but not flexible and stable enough. Firstly, the pressure equals to the weight, but it's not possible to change the value of the weight continuously, so that the pressure can't be adjusted dynamically over the processing period. Secondly, the open-loop speed controller can't eliminate the static error automatically, and it has a poor load capacity.

For the problem above, the structure was improved to Fig.3. The new structure replaces the open-loop speed controller with a closed-loop controller, which has a good load capacity and zero static error, to promote the speed control precision. Also, strain gauges and handlers replace the pulley-weight structures, which make it easy to adjust the pressure manually over the processing period.

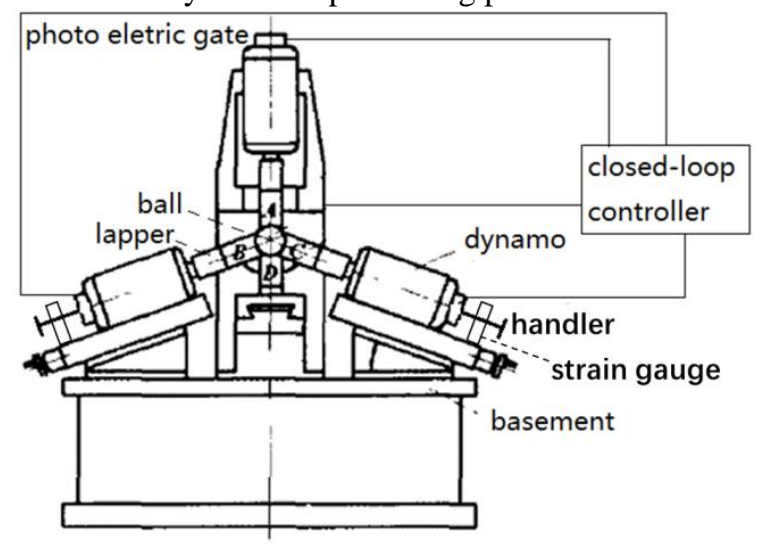

Figure 3. Four axis ball grinder after improvement.

In addition, the center deviation of the tetrahedron is also an important indicator of the uniformity of processing, When the deviation exists, the uniformity of the grinding is rapidly deteriorated. Therefore, the precision of the motor base has a great influence on the final precision of the ball. In addition, elastic couplings are implemented as supporting elements between lappers and motors, which achieves self-alignment of the lapper-ball contact ring, and improves the consistency of the alignment and the symmetry of the lappers.

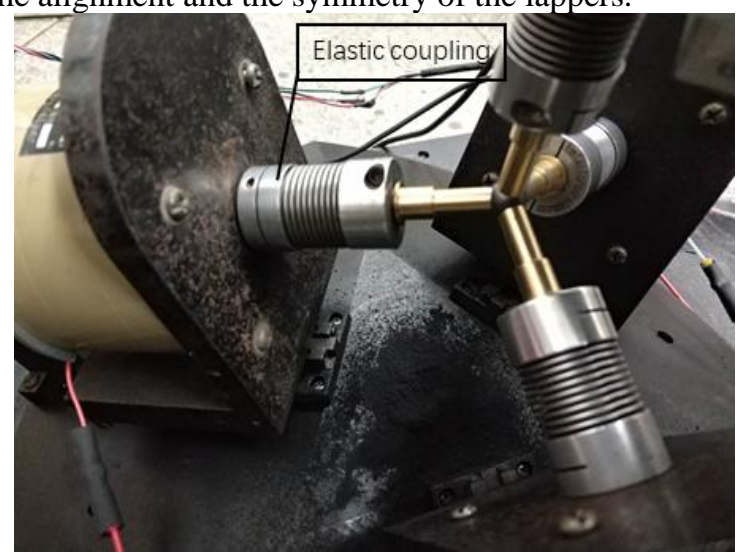

Figure 4. Improve the 4 axis ball grinder with elastic coupling.

The last factor, i.e., the grinding coefficient, is mainly related to the surface roughness. With the advancement of grinding process, the surface roughness of the graphite ball decreases, to decrease the grinding rate, so that the processing moves smoothly to the finishing stage. And when the roundness of the ball was measured by time, it can be 
seen that the processing rate become more and more slow to a stable state.

\section{GRAPHITE BALL PROCESSING EXPERIMENT WITH FOUR AXIS BALL GRINDER}

\section{A. Relationship between the Processing Time and the Roundness of the Graphite Ball}

With the four axis ball grinder, a set of $5 \mathrm{~mm}$ radius graphite balls were processed, under the circumstance of $3 \mathrm{~mm}$ radius lapper and $3 \mathrm{~N}$ pressure. The roundness of the ball was measured every other 5 minutes and Fig. 5 shows the result.

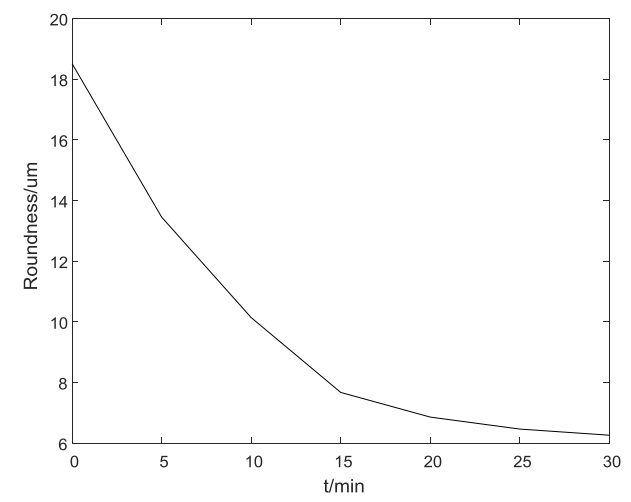

Figure 5. The relationship between the roundness of graphite ball and the processing time.

As can be seen from Fig. 5, the roundness of the graphite ball decreases gradually with the grinding process. As the grinding rate decreases, the roundness gradually approaches a fixed value (about 6um). This proves that the four axis ball grinder has a significant effect on reducing roundness of the graphite ball. At the same time, it is also proved that the surface roughness of the ball is reduced with the grinding process so that the grinding rate decreases over time, which is exactly the same as what was speculated above.

\section{B. Relationship between the Radius of Lappers and the Roundness of the Graphite Ball}

Keeping other conditions unchanged, $2 \mathrm{~mm}$ and $3 \mathrm{~mm}$ radius lappers were respectively used for grinding, the change of roundness was shown in Fig. 6.

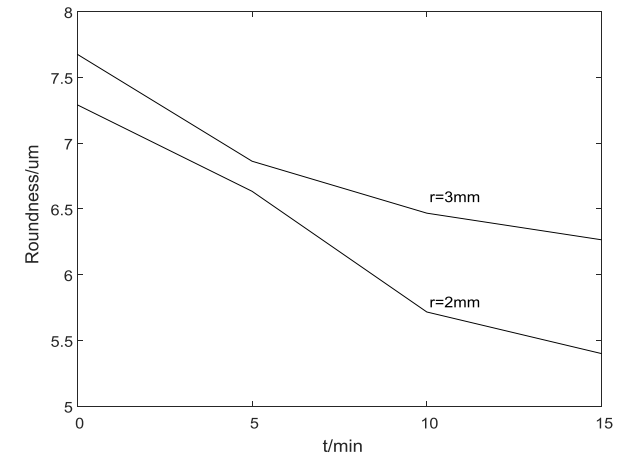

Figure 6. The relationship between the roundness of graphite ball and the lapper radius.
As can be seen from Fig. 6, the final roundness processed by the $3 \mathrm{~mm}$ lapper $(\mathrm{r} / \mathrm{R}=0.6)$ is about $6 \mathrm{um}$, and the final roundness processed by the $2 \mathrm{~mm}(\mathrm{r} / \mathrm{R}=0.4)$ lapper is about 5um. This verifies the conclusion in Table III that the processing effect is different with the use of different radius lappers. It is also proved that the combination of coarse grinding $(r / R>=0.6)$ and fine grinding $(r / R<=0.5)$ can achieve improvement of both efficiency and precision.

\section{Relationship between the Pressure and the Roundness of the Graphite Ball}

With lapper radius $3 \mathrm{~mm}, 3 \mathrm{~N}, 6 \mathrm{~N}$, and $9 \mathrm{~N}$ pressure are selected respectively to get the change of roundness shown in Fig. 7.

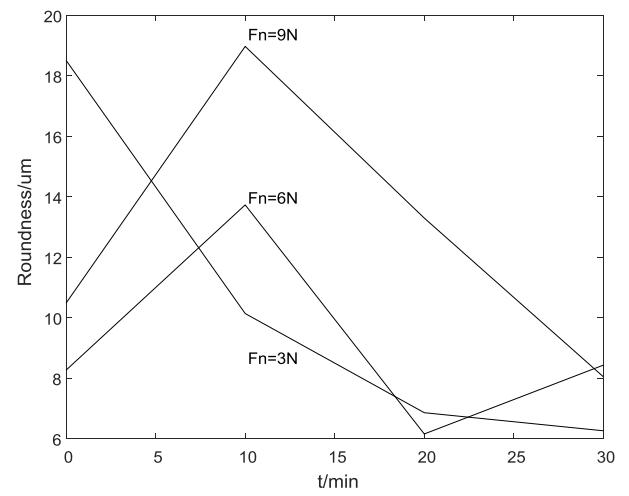

Figure 7. The relationship between the roundness of graphite ball and the pressure to the center.

With the pressure increased, the processing is accelerated. When the pressure is more than $6 \mathrm{~N}$, the processing effect is unstable. When the pressure is up to $9 \mathrm{~N}$, the processing effect can't be contemplated. The above phenomenon is due to the low surface hardness of the graphite ball. The ball is easily scratched with the pressure increasing, thus affecting the overall processing uniformity.

\section{Comparison of the Surface Roughness before and after Processing}

Grind the ball for 20 minutes with $3 \mathrm{~mm}$ radius lapper and 10 minutes with $2 \mathrm{~mm}$ radius lapper. Then the comparison of surface morphology before and after grinding by white light interferometer can be seen in Fig. 8.

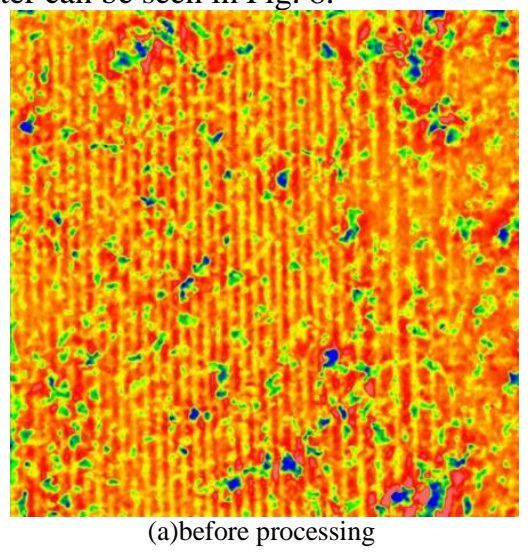




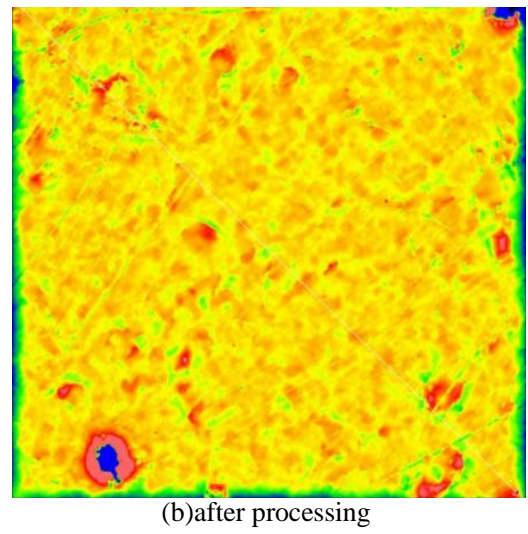

Figure 8. Photo of ball surface before and after grinding.

The measurement results show that the surface roughness has decreased from $\mathrm{Sa}=0.997 \mathrm{um}$ before grinding to $\mathrm{Sa}=0.200 \mathrm{um}$ after grinding.

\section{E. The Conclusion of the Experiments}

To sum up, when the radius of the ball is $5 \mathrm{~mm}$, and in the stage of coarse grinding, the radius of the lappers should be about $3 \mathrm{~mm}$, the pressure should be less than $3 \mathrm{~N}$, and the processing time should be $5-7 \mathrm{~min}$. In the stage of fine grinding, the radius of the lappers should be around $2 \mathrm{~mm}$, and the processing time should be 20-30min. In accordance with the above approach, the graphite ball with roundness of 5um, surface roughness (Sa) $0.200 \mathrm{um}$ can be finally machined.

\section{THE CONCLUSION}

A four axis ball grinding method for high precision graphite ball processing is presented in this paper. The structure of the four axis ball grinder and the mechanism of grinding effect are analyzed in detail. The influence from the size of lapper, the pressure and the grinding coefficient is studied. Also, these theories have been verified by experiments. Finally, in accordance with these theories, the graphite ball with roundness of $5 \mathrm{um}$ can be processed and the requirements for the quartz hemispherical resonator are satisfied. In the future, detailed mathematical model of the processing error will be studied, and the analysis to the mechanism of the grinder in this paper can be a starting point.

\section{REFERENCES}

[1] Y.H. Xiong and J. Huang, "Application of isostatic pressure graphite in 3D heating curved glass" Carbon Technology, vol.2, Apr. 2017, pp.7-9,doi: 10.14078/j.cnki.1001-3741.2017.02.002(in chinese)

[2] J. Guo, "Study on the comparison test of graphite truck milling process with isotropic pyrolysis" New Technology in China, vol.8, Apr. 2016, pp. 90-91,doi: 10.13612/j.cnki.cntp.2016.08.069(in chinese)

[3] W.W Zhang, "Research on polishing isotropic graphite" Hunan Univ. 2013(in chinese)

[4] X.M Sun, "Mechanism and test of ultra precision grinding with four axis ball grinder" Optics And Precision Engineering, vol.1, Feb. 2000, pp. 46-50(in chinese)

[5] C.G An, "Preparation and characterization of micro-nano graphite spheres" Shandong Univ,2011(in chinese)

[6] B. Shiari, T. Nagourney, A. Darvishian, J. Yoong Cho and K. Najafi, "Numerical prediction of stress evolution during blowtorch reflow of fused silica micro-shell resonators," 2016 IEEE International Symposium on Inertial Sensors and Systems, Laguna Beach, CA, 2016, pp. 13-16.doi: 10.1109/ISISS.2016.7435533.

[7] X.K. Wang, Manual of Precision Machining Technology. Beijing: China Machine, 1999(in chinese)

[8] F.W Preston, "The theory and design of plateglass polishing machines" J soc Glas Tech, vol 11, 1927, pp. 214-256

[9] X.L Yu, "Analysis of the mechanism of super precision machining with four lappers grinding machine" Journal of Tsinghua University(science and technology), vol.5, May. 2003, pp. 632-635+643, doi:10.16511/j.cnki.qhdxxb.2003.05.014(in chinese)

[10] F Marcelja, D.B Debra, G.M Keiser," Precision spheres for the Gravity Probe B experiment", Classical \& Quantum Gravity, vol.32 2015

[11] K Goto,H Mizumoto "Lapping system for ultra-precision bearing balls" Journal of Japan Society for Precision Engineering, vol.62 1996, doi: 10.2493/jjspe.62.681(in japanese)

[12] K Goto,H Mizumoto "A Lapping System for Improving the Waviness of Ultra-precision Steel Balls" Journal of Japan Society for Precision Engineering, vol.63 1997, 10.2493/jjspe.63.96(in japanese)

[13] W Angele, "Finishing high precision quartz balls", Precision Engineering, vol.2 1980, pp. 119-122. 